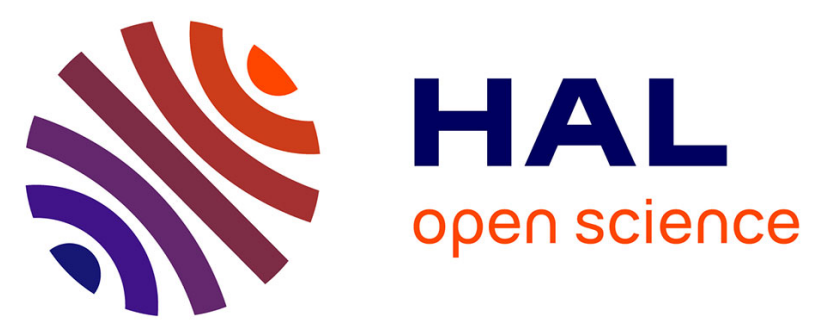

\title{
Development of Intermetallic Materials for Structural Applications : Toward Designing Multi-constituent and/or Multi-phase Alloys

\author{
S. Naka
}

\section{- To cite this version:}

S. Naka. Development of Intermetallic Materials for Structural Applications: Toward Designing Multi-constituent and/or Multi-phase Alloys. Journal de Physique IV Proceedings, 1996, 06 (C2), pp.C2-147-C2-152. 10.1051/jp4:1996220 . jpa-00254198

\section{HAL Id: jpa-00254198 https://hal.science/jpa-00254198}

Submitted on 1 Jan 1996

HAL is a multi-disciplinary open access archive for the deposit and dissemination of scientific research documents, whether they are published or not. The documents may come from teaching and research institutions in France or abroad, or from public or private research centers.
L'archive ouverte pluridisciplinaire HAL, est destinée au dépôt et à la diffusion de documents scientifiques de niveau recherche, publiés ou non, émanant des établissements d'enseignement et de recherche français ou étrangers, des laboratoires publics ou privés. 


\title{
Development of Intermetallic Materials for Structural Applications: Toward Designing Multi-constituent and/or Multi-phase Alloys
}

\author{
S. Naka \\ ONERA, 29 Avenue de la Division Leclerc, 92322 Châtillon, France
}

\begin{abstract}
The present paper emphasizes that only the designing of multi-constituent and/or multi-phase alloys can meet the requirements of real structural applications, by using several results of our recent work in ONERA, which aims at taking advantage of the huge potential offered by numerous combinations of metallic elements in intermetallics. The paper develops the following three points : 1) designing novel alloy systems showing a twophase $\gamma-\gamma^{\prime}$-type microstructure observed in Ni-base superalloys, 2) advantage of the two-phase $\gamma+\alpha$ lamellar structure and its complexity in TiAl-base alloys, 3) problems associated with the degree of order in complex B2 aluminides of refractory metals and an unusually high room-temperature tensile ductility obtained in some of them. Finally, we try to indicate the type of further contribution stemming from the work of basic research scientists, which can be useful for future activities in the development of intermetallic materials.
\end{abstract}

\section{INTRODUCTION}

The current approach for the development of intermetallic materials is essentially based on identifying binary intermetallic compounds such as nickel and titanium aluminides as well as certain silicides, exhibiting some basic promising properties. However, the number of potentially interesting compounds for structural applications is limited. Each of these binary compounds has a given crystal symmetry, and if it is complex, the compound is hardly deformable and one does not expect much macroscopic ductility even at fairly high temperatures; in other words, the compound has a ceramic-like behaviour. On the contrary, if the crystal structure is simple or less complex, there are serious prospects for ductilization and making the material workable. Numerous attempts have therefore been made in this direction both through grain size refinement or grain boundary suppression and by micro- or macro-alloying. In spite of some successful or even spectacular examples resulting from such efforts, the materials science community has yet to provide a new material which possesses an acceptable balance of mechanical and other essential properties. Thus, if we restrict ourselves only to a binary compound base, there is an obvious danger to rapidly exhaust the existing possibilities. In order to benefit from the huge potential offered by numerous combinations of metallic elements in intermetallics, we have been interested over the past few years in exploring ternary, quaternary or more complex alloy systems, the aim being to identify new intermetallic phases (absent in binary couples) having a simple crystal structure and then to evaluate their field of existence both in composition and in temperature. The objective of the present paper is to describe all these activities by using some results of our recent investigations and to illustrate the importance of exploring ternary or more complex alloy systems showing, if possible, a two-phase (or multi-phase) microstructure in order to widen the horizon of research and development effort on intermetallic materials.

\section{INTERMETALLIC MATERIALS SHOWING TWO-PHASE $\gamma$ - $\gamma^{\prime}$ TYPE MICROSTRUCTURE}

Since the lack of both ductility and toughness often represents the major drawback in intermetallics, the successful development of these new materials essentially depend on the improvement of these properties. However, it is also important to increase the mechanical strength of many intermetallic 
compounds, a consideration often overlooked by many research workers. For example, the stoichiometric or Ni-rich NiAl has a yield strength of $100-200 \mathrm{MPa}$ which is very low from the engineering viewpoint, although this strength corresponding roughly to $10^{-3} \mu$ ( $\mu$ is the shear modulus) is fairly high in view of the plasticity theory. Hardening of intrinsically strong crystals which have a high lattice friction stress is not very easy. There is, however, ample experimental evidence available today to show that the mechanical strength of multi-phase materials is higher than that of single-phase intermetallics [1]. Inspired by the outstanding mechanical performance of Ni-base superalloys, we have attempted for several years to generate two-phase $\gamma-\gamma$ type microstructures in various alloy systems, assuming that a good phase compatibility between the second phase and the matrix phase is a major factor for obtaining useful high-temperature high-strength materials. We now describe briefly the approach, the experimental results and the degree of success accomplished during this endeavour.

The first case deals with the pseudo-binary Fe-Ni2AlTi system and its derivatives. In this case, the initial idea was to incorporate the NiAl phase (B2) in a BCC (A2) matrix. Among the ternary systems $\mathrm{X}-\mathrm{Ni}-\mathrm{Al}$ ( $\mathrm{X}=\mathrm{BCC}$ transition metals such as $\mathrm{Fe}, \mathrm{Cr}, \mathrm{V}, \mathrm{Mo}, \mathrm{W}, \mathrm{Nb}$ and $\mathrm{Ta}$ ), three systems $\mathrm{Fe}-\mathrm{Ni}-\mathrm{Al}$, $\mathrm{Cr}-\mathrm{Ni}-\mathrm{Al}$ and $\mathrm{V}-\mathrm{Ni}-\mathrm{Al}$ possess a two-phase $(\mathrm{A} 2+\mathrm{B} 2)$ field in a certain composition range. It is interesting here to compare the lattice parameter of each of the above metals with that of $\mathrm{NiAl}$ (aNiAl = $0.2886 \mathrm{~nm}$ ). Both $\mathrm{Fe}$ and $\mathrm{Cr}$ have a parameter close to that of NiAl while $\mathrm{V}$ has a slightly larger parameter $\left(\left(\mathrm{aV}-\mathrm{aNiAl}_{\mathrm{N}}\right) / \mathrm{aV} \approx 0.04\right)$. All the others $(\mathrm{Mo}, \mathrm{W}, \mathrm{Nb}$ and $\mathrm{Ta})$ have a much larger parameter, especially for $\mathrm{Nb}$ and $\mathrm{Ta}$ (e.g. $(\mathrm{aNb}-\mathrm{aNiAl}) / \mathrm{aNb} \approx 0.13$ ). It is important to note the difference between the pseudo-binary $\mathrm{Fe}-\mathrm{NiAl}$ phase diagramme on the one hand and $\mathrm{Cr}-\mathrm{NiAl}$ and $\mathrm{V}-\mathrm{NiAl}$ diagrammes on the other hand. For the Fe-NiAl system, two single-phase solid solution fields, either disordered (A2) or ordered (B2), occupy the whole composition range at high temperatures and these solid solutions decompose into two phases $(\mathrm{A} 2+\mathrm{B} 2)$ at low temperatures. The other two systems show a eutectic reaction. In general, a system having the phase diagramme of the Fe-NiAl type offers a great flexibility for controlling different microstructural parameters (size and distribution of the second phase and its volume fraction) through a suitable choice of composition and heat treatments. Our experiments [2] showed that the microstructure observed in alloys of the Fe-NiAl system after solidification was indeed characterized by a very fine two-phase morphology probably due to a spinodal-like decomposition but that this microstructure is very stable during heat treatments. These alloys were therefore always very hard and brittle. When a part of $\mathrm{Al}$ is replaced by $\mathrm{Ti}$, the microstructure observed after directional solidification was found to show a morphology very similar to that of nickel-base $\gamma-\gamma^{\prime}$ alloys and characterized by a very regular distribution of cuboidal particles (size $\approx 0.2 \mu \mathrm{m}$ ) of L2 1 phase in the BCC matrix with a volume fraction of about $50 \%$ (Figure $1 \mathrm{a}$ ). The L2 1 phase is a super-structure of the BCC (A2) lattice and these two phases have a cube-cube orientation relationship but their lattice coherency is not very high (mismatch $\approx 1 \%$ ).

The second example concerns the $\mathrm{Nb}$ - and Ta-base alloys. Since both $\mathrm{Nb}$ and $\mathrm{Ta}$ have a BCC (A2) lattice, a suitable second phase may be of the B2-type. However, among about 300 binary B2 compounds inventoried in the literature, no binary B2 compound can be formed with either $\mathrm{Nb}$ or $\mathrm{Ta}$. The experiments were therefore extended both to ternary $\mathrm{Nb}-\mathrm{XY}$ and $\mathrm{Ta}-\mathrm{XY}$ and to quaternary $\mathrm{Nb}$ $\mathrm{X}_{2} \mathrm{YZ}$ and $\mathrm{Ta}-\mathrm{X}_{2} \mathrm{YZ}$ systems. The choice of $\mathrm{B} 2$-type $\mathrm{XY}$ or $\mathrm{X}_{2} \mathrm{YZ}$ compounds was made by taking into
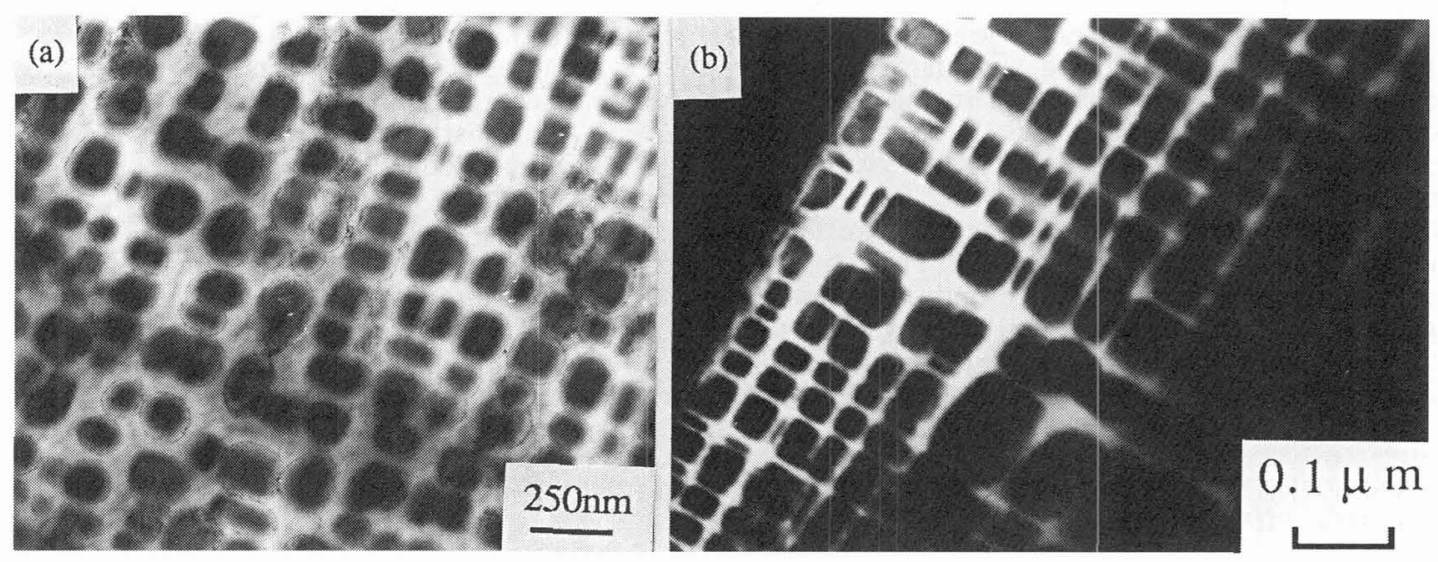

Figure 1: (a) TEM bright field image of the two-phase microstructure ( $\mathrm{A} 2+\mathrm{L} 2_{1}$ ) observed in the Fe-Ni ${ }_{2} \mathrm{AlTi}$ system, (b) TEM dark field image of the two-phase microstructure (B2+A2) obtained in a Ta-base alloy (Ta-Ti-Zr-Al-Nb-Mo system). 
account the difference in the lattice parameters between $\mathrm{Nb}$ or $\mathrm{Ta}(\mathrm{aNb}$ and $\mathrm{aNb} \approx 0.330 \mathrm{~nm}$ ) and these B2 compounds. If the difference is too large, the system cannot permit a coexistence of two phases A2 and B2. Furthermore, even if the system accepts such a coexistence, it will tend to take the shape of a phase diagramme with a eutectic reaction rather than that with a solid-state decomposition. The compatibility of two lattices may also be very low. A survey of the literature indicates that there are some ternary B2 compounds of the Ti2AlX $((X=\mathrm{Mo}, \mathrm{Fe}, \mathrm{Cr}, \mathrm{Nb})$ type. Their lattice parameters are not well known but seem to be of the order of $0.310-0.315 \mathrm{~nm}$. The field of existence of these phases, both in terms of concentration and temperature, is also not well known. Since our preliminary experiments indicated that Ti2AlMo was the most stable among the above compounds, alloys of the quaternary $\mathrm{Nb}$ $\mathrm{Ti}_{2} \mathrm{AlMo}$ and $\mathrm{Ta}-\mathrm{Ti}_{2} \mathrm{AlMo}$ systems were investigated. Microstructural examinations of numerous alloys of these systems both in the as-cast state and after heat treatments indicated that they were totally single-phased, but electron diffraction studies showed that, at room temperature, they were either disordered (A2) or ordered (B2) depending on the alloy composition. The results of these microstructural observations suggest that both of the above pseudo-binary systems shows the second order (or continuous) order-disorder transition. Work was therefore directed toward identifying suitable additional alloying elements which would make these alloy systems show the first order order-disorder transition. A successful result was obtained in an alloy of the complex Ta-base system (Ta-Ti-Zr-Al-NbMo). Starting from a quaternary Ta-Ti-Al-Mo system presenting a second order order-disorder transition, a partial substitution of $\mathrm{Zr}$ for $\mathrm{Ti}$ as well as that of $\mathrm{Nb}$ for Mo provided $\mathrm{Ta}$-rich alloys showing the two-phase B2+A2 microstructure, as illustrated in Figure 1b. The two phases (matrix and precipitates) of the observed microstructure show a cube-cube orientation relationship, and the volume fraction of regularly distributed cuboidal particles is at least $50 \%$. The examination of the interface by TEM indicates that the lattice misfit is quite small. There is however an important difference between this two-phase microstructure and that of the $\gamma-\gamma^{\prime}$ Ni-base superalloys. While the $\gamma-\gamma^{\prime}$ Ni-base superalloys are constituted by ordered $\gamma$ particles and disordered $\gamma$ matrix, it is the second phase cuboidal particles in our Ta-rich alloys that are disordered, namely BCC (A2), the matrix being ordered B2. Various attemps made since then by preparing numerous alloys of the same alloy system, in order to reverse the nature of the matrix and second phase (viz. two-phase $\mathrm{A} 2+\mathrm{B} 2$ microstructure), have been unsuccessful up to now.

\section{ADVANTAGE OF THE TWO-PHASE $\gamma+\alpha_{2}$ LAMELLAR STRUCTURE AND ITS COMPLEXITY IN TIAI-BASE ALLOYS}

Two-phase $\gamma+\alpha_{2}$ TiAl-based alloys now receive a great deal of interest because of their promising properties (i.e. high specific mechanical strengh and good oxidation resistance) for high temperature applications. It has been shown that the microstructure strongly affects the mechanical properties. In order to establish the relationship between microstructures and mechanical properties, many studies on phase transformation were carried out $[3,4]$. Due to the complexity of the phase diagram for the chemical composition range of these alloys, numerous transformation modes appearing during various heat treatments can be found: formation of a two-phase $\gamma / \alpha_{2}$ lamellar structure, $\alpha \rightarrow \alpha_{2}$ ordering reaction and $\alpha \rightarrow \gamma$ massive-type transformation, discontinuous coarsening of the lamellar structure and formation of monolithic $\gamma$ grains. Among various microstructures resulting from the above transformations, the so-

(a)

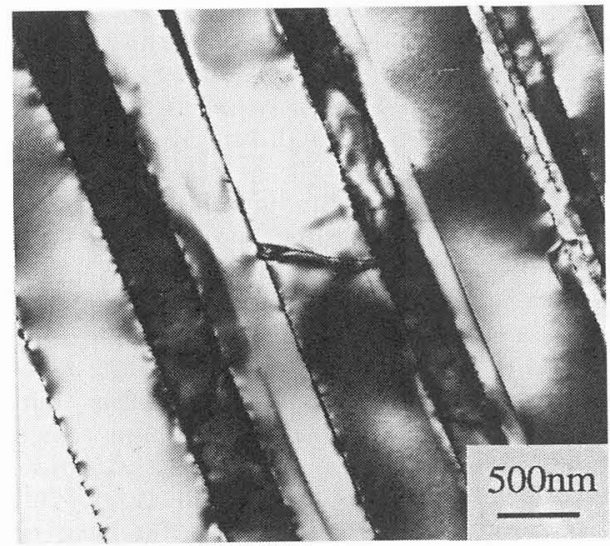

(b)

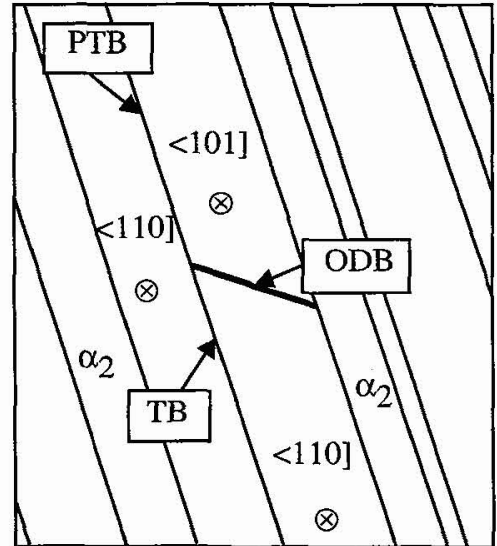

Figure 2: (a) Lamellar structure observed in two-phase $\gamma+\alpha_{2}$ TiAl-based alloys, (b) schematic representation of various interfaces observed in the lamellar structure. 
called lamellar structure (Figure 2a) is the most typical and important one.

Compared to the single-phase $\gamma$ alloys, twophase $\gamma+\alpha_{2}$ TiAl-based alloys exhibit a higher ductility. One of the possible explanations of a better ductility of these alloys is that the presence of $\alpha_{2}$ phase enhances the ductility by scavenging interstitial impurities. In order to confirm this scavenging effect, the atom probe-field ion microscopy (AP-FIM) was applied to the examination of the partitioning of interstitial elements (oxygen in particular) in two binary two-phase alloys $\left(\mathrm{Ti}_{52} \mathrm{Al}_{48}\right.$ and $\mathrm{Ti}_{54} \mathrm{Al}_{46}$ ) of the normal impurity level $(\approx 2500$ at.ppmO) [5]. Experimental results show that the majority $\gamma$ phase is significantly purified in two-phase alloys. Indeed, volume fractions of $\alpha_{2}$ phase as low as $10 \%$ are sufficient to decrease the oxygen level in the $\gamma$ phase by a factor of about 10:1

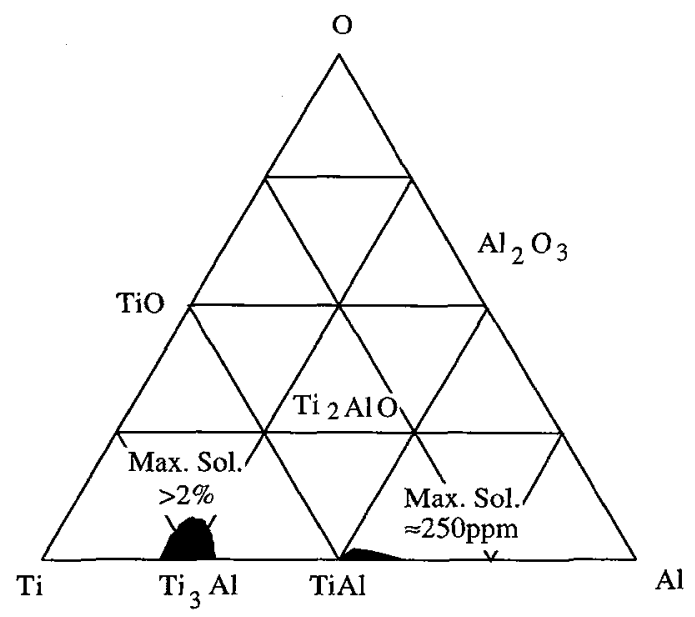
(2500 ppm in the alloy and $250 \mathrm{ppm}$ in the $\gamma$ Figure 3: Schematic representation of the ternary Ti-Al-O phase). Moreover, it is noteworthy that this phase diagramme.

purification effect can be observed even on the as-cast states and that the concentrations of oxygen or carbon in the $\gamma$ phase appear to be almost identical in the two alloys, while the volume fractions of the $\alpha_{2}$ phase are different. These results can be explained by considering the transformation sequence of these alloys. The $\mathrm{L} 1_{0} \gamma$ phase is formed from the hexagonal phase, disordered $(\alpha)$ or ordered $\left(\alpha_{2}\right)$. This $\gamma$ phase formation with a lamellar morphology is fairly fast, since controlled by the movement of Shockley partials in the hexagonal phase. The nascent $\gamma$ lamellae have presumably the same concentrations in oxygen and carbon as the initial $\alpha$ phase, that is to say, the global concentrations of those elements in the alloy. However, the concentrations experimentally determined indicate that the interstitial elements are significantly less soluble in the $\gamma$ phase than in the $\alpha_{2}$ phase. It is then the supersaturation in interstitial elements of the nascent $\gamma$ phase that promotes the transport of interstitials to the $\alpha_{2}$ phase. This phenomenon stops when the concentrations in these interstitials attain limit of solubility in the $\gamma$ phase. Moreover, since the concentrations in oxygen observed for the $\gamma$ phase are nearly identical in the two alloys, these concentrations should be close to the maximum solubility of these elements in this phase (Figure 3). However, the concentrations obtained for the $\alpha_{2}$ phase are different for the two alloys. This leads us to the conclusion that the maximum solubility of these elements in the $\alpha_{2}$ phase is greater than the experimental concentrations and is not attained, at least, for the oxygen. Otherwise, a third phase (oxide) ought to appear in order to respect the mass-balance of elements.

These experimental results suggest that the better ductility observed on two-phase alloys can then no more be explained by the presence of $\alpha_{2}$ phase, leading to a more purified $\gamma$ phase. The absence of segregated oxide precipitates in two-phase alloys would rather constitute a better explanation of the difference in ductility between two-phase and single-phase alloys. Indeed, in "nominally" single-phased alloys ( $>50$ at.\% Al) prepared by using raw titanium of the normal purity (oxygen is a major impurity element in titanium), oxygen should be strongly segregated in oxide form, while in two-phase alloys, oxygen is "dispersed" through the $\alpha_{2}$ lamellae, these lamellae being fine and quite regularly distributed throughout the alloys.

Now, it is worth describing briefly the crystallographical nature of the lamellar structure shown in Figure 2a. Resulting from the decomposition of the $\alpha$ phase on cooling, the lamellar structure is constituted by lamellae of $\alpha_{2}$ and $\gamma$ phases, following the orientation relationship: $(0001) \alpha_{2} / /\{111\} \gamma$ and $\left\langle 11 \overline{2} 0>\alpha_{2} / /<1 \overline{1} 0>\gamma\right.$. The habit plane of the two phases is the (0001) basal plane of $\alpha_{2}$. The lamellar structure is generally characterized by a set of several $\gamma$ lamellae alternating with a single $\alpha_{2}$ lamella. Note that all the $\alpha_{2}$ lamellae in a given grain are oriented in the same manner, due to the fact that $\alpha_{2}$ correspond to a simply ordered form of the initial $\alpha$ phase. By examining in more detail the $\gamma$ lamellae, it can be noticed that each $\gamma$ lamella is divided into numerous order-domains. These domains are generated due to the fact that the positions of $\mathrm{Ti}$ and $\mathrm{Al}$ atoms on the $<1 \overline{1} 0]$ and $<01 \overline{1}$ ] axes of the $\mathrm{Ll}_{0}$ structure are not equivalent. It should be noted here that the boundaries between two order-domains do not follow any particular orientation. It is also noteworthy that all the domains of a given lamella have the same stacking sequence of $\{111\}$ planes, i.e. ABCABC... or ACBACB..., while two ajacent lamellae generally have opposite stacking sequences, i.e. $\mathrm{ABCABC}$... vs $\mathrm{ACBACB}$.... The domains of the two adjacent lamellae are then twin or pseudo-twin related. As a result, the lamellar structure comprises various 
interfaces (Figure $2 b$ ); there exist $\alpha / \gamma$ interfaces and moreover order-domain boundaries (ODB), twin boundaries (TB) and pseudo-twin boundaries (PTB) for $\gamma / \gamma$ interfaces. In view of such a complexity, the author believes that detailed studies on the response of these interfaces to the straining are essential in the future for understanding the deformation behaviour of this category of alloys.

\section{COMPLEX B2 ALUMINIDES OF REFRACTORY METALS AND A VERY HIGH ROOM- TEMPERATURE TENSILE DUCTILITY OBTAINED IN SOME OF THEM}

The existense of these B2 aluminides has been identified during our investigations of last several years [6]. These complex B2 aluminides are constituted by three groups of metallic elements, namely $\mathrm{X}=(\mathrm{Ti}$, $\mathrm{Zr}, \mathrm{Hf}), \mathrm{Y}=(\mathrm{Nb}, \mathrm{Ta}, \mathrm{Mo}, \mathrm{W}, \mathrm{Cr}, \mathrm{V})$ and $\mathrm{Al}$. Thus, the alloy system is of multi-constituent type but may be considered as pseudo-ternary $\mathrm{X}-\mathrm{Y}-\mathrm{Al}$. Here, both $\mathrm{X}$ and $\mathrm{Y}$ can correspond either to an isolated element or to a combination of the elements of each group. $X$ has crystallographically a BCC (A2) structure at high temperatures whereas $\mathrm{Y}$ is always of $\mathrm{BCC}$ (A2) type. It should be pointed out that in binary couples $\mathrm{Ti}-\mathrm{Al}, \mathrm{Nb}-\mathrm{Al}, \mathrm{Zr}-\mathrm{Al}, \ldots, \mathrm{Ti}-\mathrm{Nb}, \ldots, \mathrm{Nb}-\mathrm{Al}$... etc., there is no $\mathrm{B} 2$ compound and that the solubility of the elements of the second group in the BCC phase of the elements of the first group is total or quite high. Various experiments carried out on many alloys of the X-Y-Al system suggest that starting from the composition around $\mathrm{X}_{2} \mathrm{YAl}$, there is a wide field of existence for the $\mathrm{B} 2$ phase in the above pseudo-ternary system, often extending deeply into both X and $\mathrm{Y}$ rich regions (Figure 4). Moreover, in most of the cases, the order-disorder transition (B2 $\leftrightarrow$ A2) is of the second order. One of the most important findings during these experiments is, however, the fact that there is a large variety of ordered states in these B2 aluminides and, in particular, the degree of order strongly depends both on alloy composition and on temperature. The variation in the degree of order can be found even in an as-cast ingot of a given nominal composition. In some cases, the degree of order of the B2 phase may change by precipitation of a second phase: e.g. orthorhombic (O) phase in Ti-rich $\mathrm{Ti}_{2} \mathrm{AINb}$ type alloys and $\mathrm{Nb}_{3} \mathrm{Al}$ $(\delta)$ phase in Nb-rich alloys of the Nb-Ti-Al system.

Examination of the influence of the variation of ordered state on the mechanical behaviour of B2 aluminides was performed, since some of them show an unusually large room-temperature tensile ductility for intermetallic materials after extrusion [7].

Optical microscopy of the cross-section of the bars obtained by extrusion of alloy ingots revealed a wavy contrast bearing a strong resemblance to the "van Gogh's sky" (VGS) (Figure 5). Macroscopically, the cross-section of the bars exhibited a surprisingly irregular shape instead of a standard circular one. Moreover, in their peripheral region, waves of VGS closely followed the irregular contour of the crosssection. These observations suggest that during extrusion the alloy ingots experience plastic instabilities arising from a region-to-region variation in deformability of the ingot; in other words, apparently there are soft and hard zones within the material. Examination of the deformation behaviour during extrusion, conducted by interrupting the extrusion of an ingot, showed a progressive alignment of the pre-existing dendrites parallel to the extrusion axis. Based on these observations, it is postulated that the above-

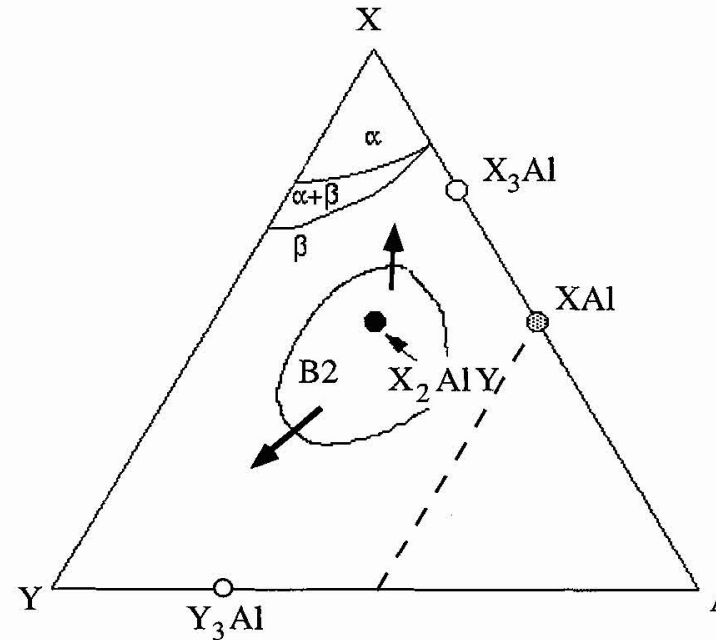

Figure 4: Field of existence of complex B2 aluminides in the pseudo-ternary diagramme.

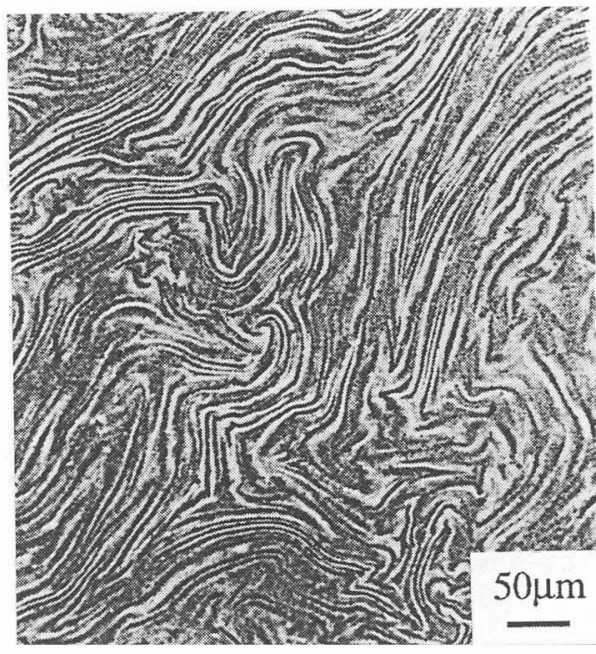

Figure 5: Example of VGS contrast, typical of the microstructures observed after extrusion. 
mentioned variation in deformability originates from the dendritic segregation. It should be mentioned here that most of the as-extruded bars were single-phased ordered B2 according to TEM examinations; hence, the VGS metallographic contrast cannot be related to precipitation of a second phase. Under these circumstances, the most plausible explanation is based on the local variation of chemical composition exemplified by etching during metallographic specimen preparation. As already mentioned, within a wide B2 phase field of the pseudo-ternary X-Al-Y system, there is a large variation in the degree of order depending both on alloy composition and on temperature, and the order-disorder transition (B2 $\leftrightarrow$ A2) is of the second order. Although detailed examinations of the ordered states have not completely been made on the B2 matrix of the alloys studied in the present work, it is probable that some variation in degree of order, which may be associated with the change of chemical composition due to dendritic segregation, plays a significant role in the variation of hardness; a low degree of order corresponds to a highly deformable soft zone, and a high degree of order to a hard zone, difficult to deform.

When tensile tests were conducted at room temperature on specimens machined from the extruded products, a very large tensile elongation $(10-28 \%)$ was obtained in many cases. Among many other interesting points remarked during these tensile tests, it is worth mentioning the following experiments. In the case of a $\mathrm{Nb}$-rich $\mathrm{Ti}_{30} \mathrm{Zr}_{1} \mathrm{Nb}_{54} \mathrm{Al}_{15}$ alloy, the ductility was $24 \%$ after extrusion at $1100^{\circ} \mathrm{C}$ and the corresponding microstructure was B2 single-phased and exhibited a typical VGS. When tensile tests were conducted on the as-cast state of the same alloy, there was no ductility. In this state, it is obvious that the alloy is free from VGS; its B2 single-phased microstructure corresponded to an ordinary dendritic type. Thus the comparison of these two results indicates a very strong ductility-enhancing effect of VGS. It is important to note here that both the dendritic structure and the VGS structure (which originates during extrusion from the dendritic segregation) are associated with a local variation of chemical composition. The difference between them is the fact that VGS is a morphologically "well organized" structure formed by an alignment of the pre-existing dendrites, compared with the dendritic structure which is more "disorganized". Examination after rupture of the VGS-bearing tensile specimen provided further useful information. The fracture surface was irregular and extremely uneven; although numerous "humps" and "troughs" of the fracture surface contained small dimples, typical of a ductile fracture, regions between humps and troughs bore more brittle features. Moreover, the tensile specimen, initially cylindrical, exhibited quite an irregular contour. All these observations strongly suggest that during the room temperature tensile test the deformation behaviour is composite-like with the presence of soft and hard zones, as observed during high temperature extrusion.

\section{CONCLUSIONS}

In this paper, the author has presented several results of our recent work in ONERA in order to emphasize that only the designing of multi-constituent and/or multi-phase alloys can meet the requirements of real structural applications. The paper also aimed at showing how materials scientists and engineers take advantage of the knowledge of modern alloy theory, pertinent to the development of useful structural intermetallics and the type of further contribution that is expected from basic research work.

\section{References}

[1] T. Khan, P. Caron and S. Naka, "Mechanical behaviour of Ni3Al-based intermetallics and the need for designing multiphase alloys", Proceedings of the Joint ASM/TMS Symposium on High Temperature Aluminides and Intermetallics, Indianapolis, TMS, Warrendale, USA (1989) pp. 219-241.

[2] S. Naka, M. Thomas and T. Khan, Materials Science and Technology, 8 (1992) 291-298.

[3] A. Denquin and S. Naka, Acta Metallurgica et Materialia, 44 (1996) 343-352.

[4] A. Denquin and S. Naka, Acta Metallurgica et Materialia, 44 (1996) 353-366.

[5] A. Denquin and S. Naka, A. Huguet et A. Menand, Scripta Metallurgica et Materialia, 28 (1993) 1131-1136.

[6] S. Naka, M. Thomas, M. Marty, G. Lapasset and T. Khan, "Complex B2 aluminides of refractory metals: an attempt to explore novel alloy systems", Proceedings of the $1^{\text {st }}$ International Symposium on Structural Intermetallics, Seven Springs, Pennsylvania, TMS, Warrendale, USA (1993) pp. 647-656.

[7] S. Naka, M. Marty, M. Thomas and T. Khan, Materials Science and Engineering, A 192/193 (1995) 69-76. 